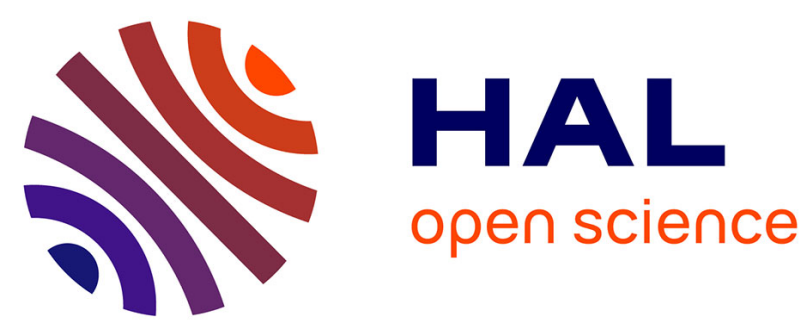

\title{
THE CONTACT CHARGE DENSITIES OF 4s ELECTRONS OF Fe IMPURITY ATOM IN SOME TRANSITION AND NOBLE METALS
}

T. Shinohara, M. Fujioka, H. Onodera, K. Hisatake, H. Yamamoto, H. Watanabe

\section{To cite this version:}

T. Shinohara, M. Fujioka, H. Onodera, K. Hisatake, H. Yamamoto, et al.. THE CONTACT CHARGE DENSITIES OF 4s ELECTRONS OF Fe IMPURITY ATOM IN SOME TRANSITION AND NOBLE METALS. Journal de Physique Colloques, 1974, 35 (C6), pp.C6-215-C6-219. 10.1051/jphyscol:1974625 . jpa-00215782

HAL Id: jpa-00215782

https://hal.science/jpa-00215782

Submitted on 1 Jan 1974

HAL is a multi-disciplinary open access archive for the deposit and dissemination of scientific research documents, whether they are published or not. The documents may come from teaching and research institutions in France or abroad, or from public or private research centers.
L'archive ouverte pluridisciplinaire HAL, est destinée au dépôt et à la diffusion de documents scientifiques de niveau recherche, publiés ou non, émanant des établissements d'enseignement et de recherche français ou étrangers, des laboratoires publics ou privés. 


\title{
THE CONTACT CHARGE DENSITIES OF 4S ELECTRONS OF Fe IMPURITY ATOM IN SOME TRANSITION AND NOBLE METALS
}

\author{
T. SHINOHARA, M. FUJIOKA $\left({ }^{*}\right)(* *)$, H. ONODERA, K. HISATAKE $(*)$ \\ H. YAMAMOTO and $\mathrm{H}$. WATANABE
}

The Research Institute for Iron, Steel and Other Metals, Tohoku University, Sendai, Japan

\begin{abstract}
Résumé. - Les électrons de conversion interne des couches $M$ et $N$ de la transition de 14,4 keV de ${ }^{57} \mathrm{Fe}$ diffusé dans des matrices de $\mathrm{Cr}, \mathrm{Ni}, \mathrm{Cu}, \mathrm{Pt}$ et $\mathrm{Au}$ ont été mesurés à l'aide d'un spectromètre $\beta$ de haute résolution.

La densité de charge des électrons $4 \mathrm{~s}(\rho$ ts $(0))$ de l'impureté de $57 \mathrm{Fe}$ dans ces matrices métalliques a été déduite à partir des intensités relatives des électrons de conversion analysées à l'aide d'une méthode de déconvolution. On a trouvé que les densités de charge au contact $4 \mathrm{~s}$ de $57 \mathrm{Fe}$ dans ces diverses matrices métalliques, ainsi que dans Fe et Co métalliques, sont pratiquement égales. Ceci indique que la densité de charge au contact $3 \mathrm{~s}\left(\rho_{3 \mathrm{~s}}(0)\right)$ joue un rôle important dans la variation du déplacement isomérique de ${ }^{57} \mathrm{Fe}$ dans ces alliages.
\end{abstract}

Abstract. - The internal conversion electrons from $M$ and $N$ shells of the $14.4 \mathrm{keV}$ transition of ${ }^{57} \mathrm{Fe}$ diffused into $\mathrm{Cr}, \mathrm{Ni}, \mathrm{Cu}, \mathrm{Pt}$ and $\mathrm{Au}$ substrates were measured using a high-resolution $\beta$-ray spectrometer.

From relative intensities of conversion electrons analyzed using a deconvolution method, we deduced the contact charge density of $4 \mathrm{~s}$ electrons $\rho_{48}(0)$ of $57 \mathrm{Fe}$ impurity atom in these host metals. The $4 \mathrm{~s}$ contact charge density of ${ }^{57} \mathrm{Fe}$ embedded in these host metals, as well as Fe and Co metals, is found to be nearly equal. This fact indicates that the 3 s contact charge density $\rho_{3 s}(0)$ plays an important role in the variation of the isomer shift of $57 \mathrm{Fe}$ in these alloys.

1. Introduction. - The Mössbauer isomer shift may be written as [1]

$$
\delta=C\left[\rho_{\mathrm{a}}(0)-\rho_{\mathrm{s}}(0)\right] \frac{\Delta R}{R}=C \cdot \Delta \rho \cdot \frac{\Delta R}{R}
$$

where $\Delta R / R$ is the fractional change of the nuclear charge radius $(R)$ between the excited and ground states, and $\rho_{\mathrm{s}}(0)$ and $\rho_{\mathrm{a}}(0)$ are the total s electron densities at the nuclei for source and absorber, respectively [1]. The notation $C$ is the calibration constant consisting of purely nuclear factors except the relativistic correction factor [1].

The isomer shift has provided valuable information in many braches of studying the atomic state. Concerning only with ${ }^{57} \mathrm{Fe}$, the value of $\Delta R / R$ has been deduced by many authors but it is far from agreement [2]: Therefore, it has been considered that in those analyses inaccurate wave functions were used [2]. Recently, Rüegsegger et al. has determined $\Delta R / R$ to be $-(3.1+0.6) \times 10^{-4}$ by measuring the nuclear life time of ${ }^{57} \mathrm{Fe}$ in different atomic environments [3]. At present this method is considered to be the most reliable, since it is free from the assumption that only

(*) Department of Applied Physics, Tokyo Institute of Technology, Meguro, Tokyo, Japan.

(**) Present address : Department of Physics, Tohoku University. $\rho_{4 s}(0)$ is sensitive to the atomic environment [3]. However, this value of $\Delta R / R$ demands $\Delta \rho$ to be much larger than that has ever been estimated.

To the elucidation of such a problem internal conversion measurement is very useful [4]. For the $M_{1}$ transitions, the $s$ electron conversion is dominant : $\alpha_{\mathrm{s}} \sim 10 \alpha_{\mathrm{p}_{1 / 2}} \sim 10^{2} \alpha_{\mathrm{p}_{3 / 2}}$ and with the accuracy of a few percents, the following relation holds [4-9]:

$$
\alpha_{i}=\text { const } \rho_{i}(0),
$$

where the index $i$ denotes the different $s$ shells involved in internal conversion. Then, assuming the atomic environment to have an influence only on the valence electrons, we can obtain the relation :

$$
\delta=C \cdot \frac{\Delta R}{R} \cdot \rho_{n_{\mathrm{c} s}} \cdot \frac{\Delta \alpha_{n_{v} \mathrm{~s}}}{\alpha_{n_{\mathrm{c} s}}} .
$$

In this equation $n_{\mathrm{v}}$ is the principal quantum number of the valence $\mathrm{s}$ electrons and $n_{\mathrm{c}}$ that of the core $\mathrm{s}$ electrons nearest to the valence shell. If one uses the theoretical value of $\rho_{n_{c} s}(0)$, one can deduce $\Delta R / R$ from a measurement of $\alpha_{n_{v} s} / \alpha_{n_{\mathrm{c}} \mathrm{s}}$ versus the isomer shift ; a recent successful example was given for ${ }^{125} \mathrm{Te}$ [10].

Previously, we deduced $\rho_{4 s}(0)$ of ${ }^{57} \mathrm{Fe}$ in $\mathrm{Fe}$ and Co metals from measurement of conversion spectra of the $14.4 \mathrm{keV}$ transition of ${ }^{57} \mathrm{Fe}$ diffused in these metals 
using a high-resolution $\beta$-ray spectrometer [11-12]. We have further extended this method to the measurement of $\rho_{4 s}(0)$ of an Fe impurity atom in some transition and noble metals.

The results give the first experimental indication that the 3 s contact charge density plays an important role in the isomer shift of these alloy systems.

2. Experiment and analysis. -2.1 Preparation OF THE SAMPLES. - The method of sample preparation was similar to that described earlier [12]. Prior to the following procedure, ${ }^{57} \mathrm{CoCl}_{2}$ in dilute $\mathrm{HCl}$ was purified with an ion exchange method using anion-exchange resin in $\mathrm{HCl}$ media. The radioactive ${ }^{57} \mathrm{Co}$ was electroplated onto the surface of various host metals in the form of foil or crystal piece, at a current density of $\sim 100 \mathrm{~mA} / \mathrm{cm}^{2}$. The electrolyte was similar to those described previously [12]. The dimension of the electroplated region was $1 \mathrm{~mm} \times 10-15 \mathrm{~mm}$. The source intensity was $100-300 \mu \mathrm{Ci}$.

Before the plating of ${ }^{57} \mathrm{Co}$ the metal samples of $\mathrm{Ni}$, $\mathrm{Cu}, \mathrm{Pt}$ and $\mathrm{Au}$ were annealed for recrystallization and degassing in vacuum. After the plating most of the samples were put into a furnace with a temperature of $400-500^{\circ} \mathrm{C}$ under hydrogen atmosphere and were slowly cooled after $10 \mathrm{~min}$. Then they were annealed at the same temperature in vacuum for a few minutes and were subjected to quenching. In this stage, we measured the Mössbauer spectrum to check whether they were the desired ones or not. If they were not the desired ones, the treatment in vacuum was repeated at a higher temperature until we obtained the desired samples.

The temperatures and the Mössbauer spectra in the last stage for these samples are given in table I and figure 1 , respectively. The hydrogen atmosphere was not used for the sample of ${ }^{57} \mathrm{Co}$ in $\mathrm{Cr}$. The samples treated thermally after plating are denoted as ${ }^{57} \mathrm{Co}$ in $\mathrm{Pt}$, etc. whereas those not treated as ${ }^{57} \mathrm{Co}$ on $\mathrm{Cr}$, etc.

\subsection{Measurement AND ANALYSIS OF THE MöSSBAuer} SPECTRA, - The Mössbauer spectrometer used to obtain figure 1 was a standard one from Elron. The Mössbauer spectra of the standard source of ${ }^{57} \mathrm{Co}$ in stainless steel and in $\mathrm{Cu}$ are also shown in figure 1 . The measurements were made at room temperature in a transmission geometry with a stationary source and a moving absorber. The source-absorber distance was 20-30 mm. The absorbets were a 0.001 inch stainless steel (SS) foil or a potassium nitroprusside polycrystal sample of $0.63 \mathrm{mg} / \mathrm{cm}^{2}$ in ${ }^{57} \mathrm{Fe}$.

In the analysis of the Mössbauer spectra, the center of an absorption dip (here after denoted as CD) was defined as the center of the full width at half maximum. For ${ }^{57} \mathrm{Co}$ in $\mathrm{Ni}$, the center of the spectrum (CS) was determined as a simple average of six CD's. For ${ }^{57} \mathrm{Co}$ on $\mathrm{Cr}$ and on $\mathrm{Au}, \mathrm{CS}$ was defined as the center of gravity of the absorption spectrum. The sample of ${ }^{57} \mathrm{Co}$ in $\mathrm{Cu}$ exhibited a satellite besides the main dip, and from the latter the CS was determined. Every measurement was sandwiched with two measurements with

\section{TABLE I}

Thermal treatments, the Mössbauer data, intensity ratios of conversion lines and $4 \mathrm{~s}$ contact charge densities for various samples of ${ }^{57} \mathrm{Co}$

\begin{tabular}{|c|c|c|c|c|c|c|c|}
\hline & & & $57 \mathrm{Fe}$ in metals & & & ${ }^{57} \mathrm{Fe} \mathrm{o}$ & on metals \\
\hline & $(\mathrm{Cr})\left({ }^{d}\right)$ & $\mathrm{Ni}$ & $\mathrm{Cu}\left({ }^{e}\right)$ & $\mathrm{Pt}$ & $\mathrm{Au}$ & $\mathrm{Cr}$ & $\mathrm{Au}(f)$ \\
\hline $\begin{array}{l}\text { Thermal treat- } \\
\text { ment }(a) \text { in } \\
\text { vacuum }\end{array}$ & $\begin{array}{l}600^{\circ} \mathrm{C} \\
\times \quad 30 \mathrm{~min}\end{array}$ & $\begin{array}{l}670^{\circ} \mathrm{C} \\
\times 1 \mathrm{~min}\end{array}$ & $\begin{array}{l}620^{\circ} \mathrm{C} \\
\times 1 \mathrm{~min}\end{array}$ & $\begin{array}{l}705^{\circ} \mathrm{C} \\
\times 2 \mathrm{~min}\end{array}$ & $\begin{array}{r}625^{\circ} \mathrm{C} \\
\times 1 \mathrm{~min}\end{array}$ & no & no \\
\hline $\begin{array}{l}\text { Isomer shift }\left(^{b}\right) \\
\text { rel. to } \mathrm{Fe}\end{array}$ & $+0.01 \pm 0.05$ & $-0.01+0.05$ & $-0.23+0.05$ & $-0.34+0.02$ & $-0.65+0.02$ & $-0.185+0.015$ & $-0.700+0.078$ \\
\hline$I_{\mathbf{M}_{2,3}} / I_{\mathbf{M}_{1}}$ & $\begin{array}{r}0.0687 \\
+0.0054\end{array}$ & $\begin{array}{r}0.0800 \\
\pm 0.0077\end{array}$ & $\begin{array}{r}0.0991 \\
+0.0076\end{array}$ & $\begin{array}{r}0.0898 \\
+0.0092\end{array}$ & $\begin{array}{r}0.0875 \\
+0.0098\end{array}$ & $\begin{array}{r}0.0844 \\
+0.0053\end{array}$ & $\begin{array}{r}0.0775 \\
\pm 0.0053\end{array}$ \\
\hline$I_{\mathrm{N}_{1}} / I_{\mathrm{M}_{1}}$ & $\begin{array}{r}0.0425 \\
\pm 0.0037\end{array}$ & $\begin{array}{r}0.0468 \\
\pm 0.0052\end{array}$ & $\begin{array}{r}0.0433 \\
\pm 0.0042\end{array}$ & $\begin{array}{r}0.0420 \\
\pm 0.0058\end{array}$ & $\begin{array}{r}0.0497 \\
\pm 0.0065\end{array}$ & $\begin{array}{r}0.0341 \\
\pm 0.0019\end{array}$ & $\begin{array}{r}0.0327 \\
\pm 0.0025\end{array}$ \\
\hline$\rho_{4 \mathrm{~s}}(0)$ in $\mathrm{a}_{0}^{-3}{ }^{(c)}$ & $\begin{array}{r}5.55 \\
\pm 0.50\end{array}$ & $\begin{array}{r}6.11 \\
\pm 0.71\end{array}$ & $\begin{array}{r}5.65 \\
\pm 0.57\end{array}$ & $\begin{array}{r}5.48 \\
+0.78\end{array}$ & $\begin{array}{r}6.49 \\
\pm 0.88\end{array}$ & $\begin{array}{r}4.45 \\
\pm 0.26\end{array}$ & $\begin{array}{r}4.27 \\
\pm 0.34\end{array}$ \\
\hline
\end{tabular}

(a) See the text.

$\left({ }^{b}\right)$ Source isomer shift relative to Fe metal.

(c) Contributions from $3 \mathrm{~d}$ and $4 \mathrm{p}$ electrons were connected by subtracting $4 \%$ of the $\mathrm{N}_{1}$ intensity and corrected to $\rho_{4 \mathrm{~s}}(0)$ using $\rho_{3 \mathrm{~s}}(0)_{\text {theor }}=136.0+2.0 \mathrm{a}_{0}^{-3}$ (ref. 12).

$\left({ }^{d}\right)$ Isomer shift of this sample did not agree with the literature value.

(e) Estimated contribution from $\mathrm{FeO}$ impurity was corrected for.

( $f$ ) Analyzed by itself. 

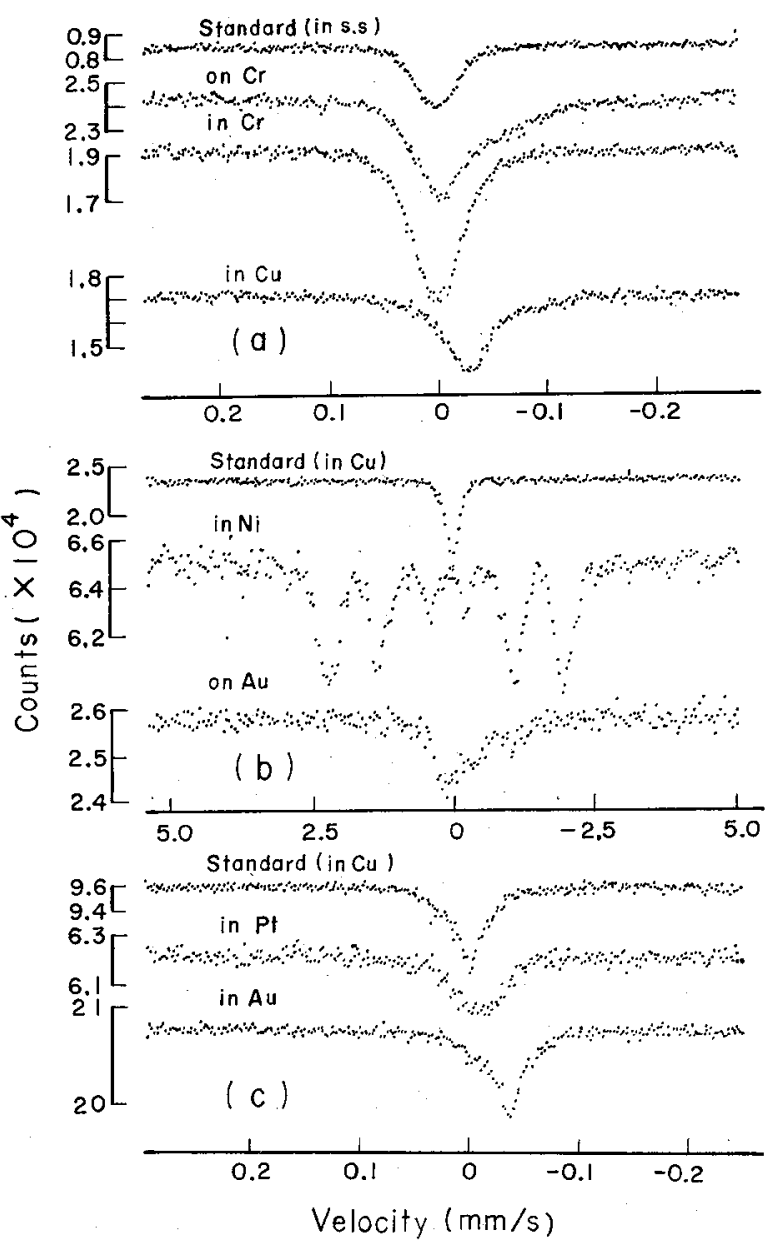

FIG. 1. - Mössbauer spectra of $57 \mathrm{Co}$ diffused into or deposited onto several metals taken at room temperature in an absorber driving mode. a) Mössbauer spectra of the samples of $57 \mathrm{Co}$ on $\mathrm{Cr}$, in $\mathrm{Cr}$, and in $\mathrm{Cu}$ together with the spectrum of a standard source of ${ }^{57} \mathrm{Co}$ in stainless steel. $b$ ) Mössbauer spectra of the samples of ${ }^{57} \mathrm{Co}$ in $\mathrm{Ni}$ and on $\mathrm{Au}$ together with the spectrum of a standard source of $57 \mathrm{Co}$ in $\mathrm{Cu}$. The absorber was $0.001^{\prime \prime}$ stainless steel.c) Mössbauer spectra of the samples of ${ }^{57} \mathrm{Co}$ in Pt and in $\mathrm{Au}$ together with the spectrum of a standard source of ${ }^{57} \mathrm{Co}$ in $\mathrm{Cu}$. The absorber was $\mathrm{K}_{4} \mathrm{Fe}(\mathrm{CN})_{6} 3 \mathrm{H}_{2} \mathrm{O}$ powder with a thickness of $0.63 \mathrm{mg} / \mathrm{cm}^{2}{ }^{57} \mathrm{Fe}$.

the standard source and from the difference of the CD's of the latter was estimated the experimental error of the CS of the former. The isomer shifts obtained are given in table I, where they have been converted into those relative to $\mathrm{Fe}$ metal using

$$
\delta\left({ }^{57} \mathrm{Fe} \text { in } \mathrm{Cu}\right)-\delta\left({ }^{57} \mathrm{Fe} \text { in } \mathrm{Fe}\right)=-0.233 \mathrm{~mm} / \mathrm{s}
$$

and

$$
\delta\left({ }^{57} \mathrm{Fe} \text { in } \mathrm{Cu}\right)-\delta\left({ }^{57} \mathrm{Fe} \text { in } \mathrm{SS}\right)=-0.323 \mathrm{~mm} / \mathrm{s} .
$$

The isomer shift thus obtained for most of the samples is consistent with the literature value [13]. For the case of ${ }^{57} \mathrm{Co}$ in $\mathrm{Cu}$, we can attribute a weak satellite to ${ }^{57} \mathrm{Co}$ in $\mathrm{FeO}$ from the isomers shift [14]. Since the recoilless fraction of $\mathrm{FeO}$ is unknown, we use the Debye model. Using $\theta=372 \mathrm{~K}$ and $324 \mathrm{~K}$ as the Debye temperature for $\mathrm{Cu}$ metal and $\mathrm{Fe}_{3} \mathrm{O}_{4}[15,16]$ respectively, we get an estimation that about $4.3 \%$ of the source intensity is due to ${ }^{57} \mathrm{Co}$ in $\mathrm{FeO}$. This fact is taken into account in the analysis of conversion spectrum. The isomer shift for ${ }^{57} \mathrm{Co}$ in $\mathrm{Cr}$ is definitely different from the previous value [13]. ${ }^{57} \mathrm{Co}$ must have diffused into a complex surface layer of $\mathrm{Cr}$ substrate because of no preheating before the plating. ${ }^{57} \mathrm{Co}$ on $\mathrm{Au}$ and on $\mathrm{Cr}$ is revealed to be in complex physical states from the spectra.

\subsection{MEASUREMENT AND ANALYSIS OF CONVERSION} SPECTRA. - The conversion electrons of the $14.4 \mathrm{keV}$ transition of ${ }^{57} \mathrm{Fe}$ emitted from the samples of ${ }^{57} \mathrm{Co}$ in and on various substrates described in the previous section were measured with a high-resolution $\beta$-ray spectrometer of the Institute for Nuclear Study, University of Tokyo [17].

The momentum resolution of the spectrometer was set to $0.05 \%$. The conversion electrons were detected after momentum analysis by a small-volume gas-flowtype proportional counter. Because the window was a thin film of VYNS with a cut off energy for electrons $E_{\mathrm{c}} \sim 1.5 \mathrm{keV}$, the electron detection efficiency of the detector was expected to be practically constant over the energy range covered by the present experiment.

The $\mathrm{M}_{1}-\mathrm{N}_{1}$ part of the spectra are shown in figure 2. As seen from this figure, the conversion lines

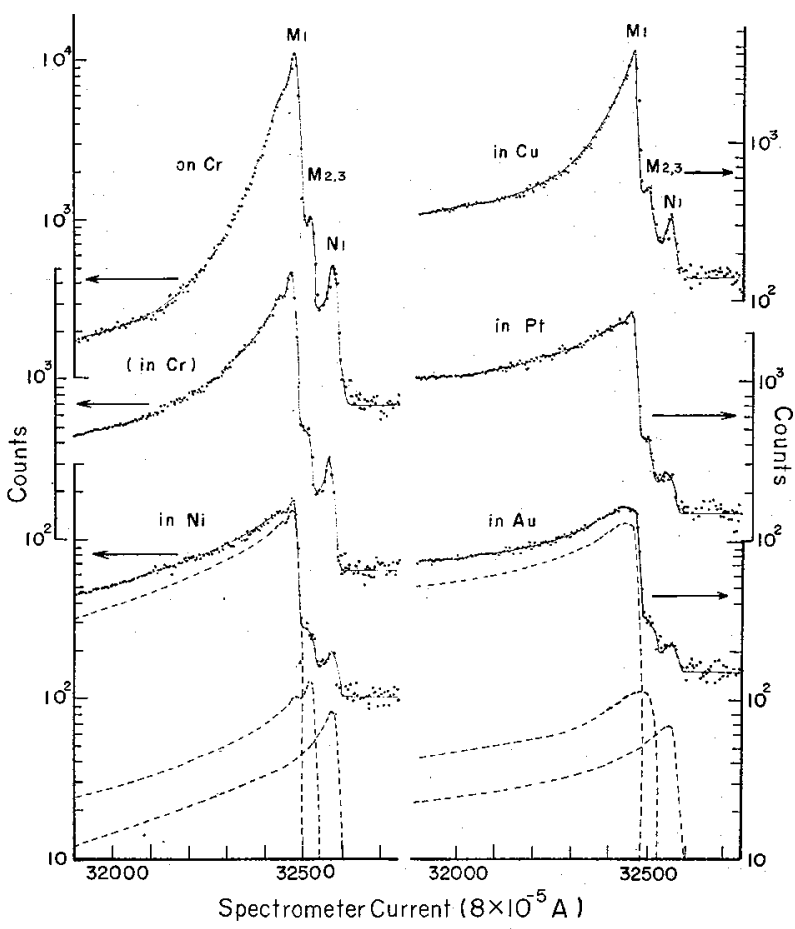

Fig. 2. - The $\mathrm{M}$ and $\mathrm{N}$ shell conversion spectra of the same samples which were used in the Mössbauer measurement. Solid curves are the results of least squares fitting. Each line profile for ${ }^{57} \mathrm{Co}$ in $\mathrm{Ni}$ and in $\mathrm{Au}$ is shown in broken curve as examples. The $M_{1}$ and $M_{2,3}$ profiles are assumed to be the same. The counting time was $25 \mathrm{~min}$ per point for all the samples but for the samples of ${ }^{57} \mathrm{Co}$ in and on $\mathrm{Cr}$ it was $15 \mathrm{~min}$ per point. 
are best resolved for the samples of ${ }^{57} \mathrm{Co}$ on $\mathrm{Cr}$ and on $\mathrm{Au}$. For the analysis of the spectra; the conversion line profiles were constructed with the deconvolution method combined with the rule of constant tail-tototal ratios [21]. The samples of ${ }^{57} \mathrm{Co}$ on $\mathrm{Cr}$ and on $\mathrm{Au}$ were intended as the reference source, but it was found that the spectrum of ${ }^{57} \mathrm{Co}$ on $\mathrm{Au}$ could not be used as a reference for the reason of the very long tail of the line profile. On the other hand, the spectrum of ${ }^{57} \mathrm{Co}$ on $\mathrm{Cr}$ worked well as a reference. We reanalyzed the previous spectra of ${ }^{57} \mathrm{Co}$ in $\mathrm{Fe}$ and in $\mathrm{Co}$ using the new reference of ${ }^{57} \mathrm{Co}$ on $\mathrm{Cr}$ and obtained essentially the same results as the previous ones obtained with the reference of ${ }^{57} \mathrm{Co}$ on $\mathrm{Co}$. The spectrum of ${ }^{57} \mathrm{Co}$ on $\mathrm{Au}$ was analyzed by itself.

Using the line profiles obtained by the present procedure and a constant background, the observed spec-

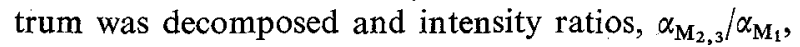
$\alpha_{N_{1}} / \alpha_{M_{1}}$ were determined by a least squares method, where a chi square test was performed and statistical errors were calculated. The tail part of the line intensity which was not covered by the measurement was approximated by an extrapolation with an exponential function.

Besides the statistical errors, we included the errors which were caused by other origins as follows. The extrapolation part for $M_{1}$ and $M_{2,3}$ lines were expected to have errors of $10 \%$. For $\mathrm{N}_{1}$ line we took an error of $10 \%$ on the lower energy side than the channel where $M_{23}$ and $N_{1}$ lines cross each other. On the higher energy side, errors of counts for $M_{1}$ and $M_{2,3}$ lines were expected to be within $20 \%$ in those channels where the count became to be lowet than the half of the peak value.

So far we have not considered the effect of the conversion electrons due to $3 \mathrm{~d}$ and $4 \mathrm{p}$ electrons, which is small but can not completely be neglected. We assumed that the contribution to the $\mathrm{N}_{1}$ line amounted to a fraction of $4 \%$ similarly as for Fe metal [12].

For the sample of ${ }^{57} \mathrm{Co}$ in $\mathrm{Cu}$, the contribution from ${ }^{57} \mathrm{Co}$ in $\mathrm{FeO}$ was corrected, assuming that $\rho_{4 \mathrm{~s}}(0)$ is zero for ${ }^{57} \mathrm{Fe}$ in $\mathrm{FeO}$. We deduced the value of $\rho_{45}(0)$ using a theoretical value of $\rho_{3 \mathrm{~s}}(0)=136.0 \pm 2.0$ a. u. [1.2] ; $\rho_{4 s}(0)=\left(\alpha_{N_{1}} / \alpha_{M_{1}}\right)_{\text {exp }} . \rho_{3 s}(0)_{\text {theor. }}$. The final result is shown in table I. It is to be noted that the present values of $\rho_{4 s}(0)$ are the non-relativistic ones as is $\rho_{3 \mathrm{~s}}(0)_{\text {thear }}$.

3. Discussion. - Let us consider the $4 \mathrm{~s}$ contact charge density, $\rho_{4 s}(0)$, deduced from the present experiment. Initially, we intended to find out a variation of $\rho_{48}(0)$ on a naive assumption that the isomer shift of ${ }^{57} \mathrm{Fe}$ in various host metals reflects directly the variation of $\rho_{4 \mathrm{~s}}(0)$; use of $\Delta R / R \sim-4 \times 10^{-4}$ predicts $\Delta \rho_{4 s}(0) \sim-4.5$ a. u. between ${ }^{57} \mathrm{Fe}$ in $\mathrm{Fe}$ and in $\mathrm{Au}$ metals $[3,18]$. Contrary to this expectation, we could not find such a variation as shown in table $I$ and figure 3. In figure 3 is also plotted the relation between $\rho_{4 s}(0)$ and $\delta$ obtainable if the value of Rüegsegger

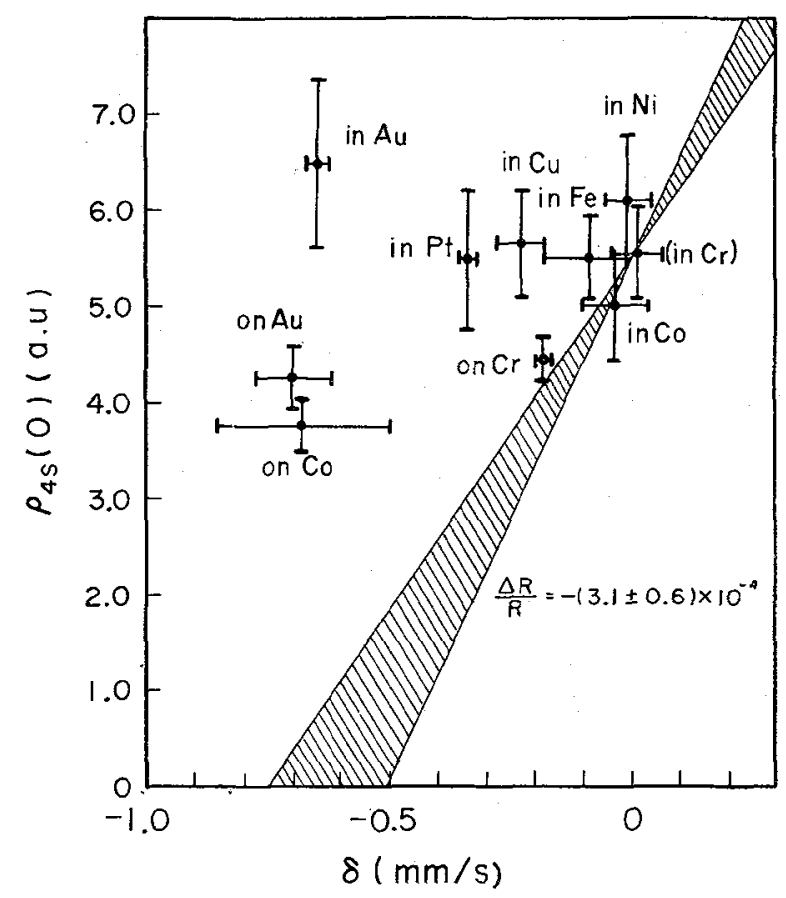

FIG. 3. - Contact charge densities obtained from the conversion measurement versus the isomer shift obtained from the Mössbauer measurement; see the text for details.

et al. [3] for $\Delta R / R$ is used and the core contribution is neglected; the constant term was so adjusted that it passed through an ideal (not experimental) point of ${ }^{57} \mathrm{Fe}$ in Fe. Discrepancy between the present result of $\rho_{4 s}(0)$ and the value of $\Delta R / R$ is apparent, and it should be attributed to a core contribution $\Delta \rho_{3 \mathrm{~s}}(0)$. This conclusion is not consistent with the recent interpretations of the isomer shift for these alloys [2], [19]. If we use an estimated value of $\beta$ under the assumption [20] of $\Delta \rho_{3 s}(0)=\beta \cdot n_{\mathrm{d}}$, we can convert $\Delta \rho_{3 \mathrm{~s}}(0)$ into the variation of $3 \mathrm{~d}$ population, $\Delta n_{\mathrm{d}}$.

We now consider the value of $\alpha_{\mathrm{M}_{2,3}} / \alpha_{\mathrm{M}_{1}}$. Since the $3 \mathrm{~s}$ and $3 p$ electrons should be relatively insensitive to the atomic environment, this ratio is expected to be constant within the experimental error. But as seen in table $I$, there is a scatter of this value, which can not be explained physically. Since the $\mathrm{M}_{2,3}$ line is sandwiched between the $M_{1}$ and $N_{1}$ lines, we could not determine a reliable profile of this and the $M_{1}$ profile was employed instead, which might be a cause of such scatter. Indeed, from our preliminary measurement of $L$ conversion spectra, the shape of the $L_{2,3}$ line was found to be different from that of the $L_{1}$ line, and an analysis taking this difference into account gave values of $\alpha_{L_{2,3}} / \alpha_{L_{1}}$ which were constant for all the samples within the experimental error. However, as seen in table $\mathrm{I}$, such an uncertainly of the $\mathrm{M}_{2,3}$ line profile could not effect so much on the above conclusion.

At present we can not draw too detailed a conclusion concerning each of the host metal investigated, and it seems desirable to extend the scope of such an experi- 
ment and to reduce the experimental error as far as possible. At the same time, a reliable determination of $\Delta R / R$ for ${ }^{57} \mathrm{Fe}$ is very important. To do so, very accurate determination of $\left(\alpha_{M_{1}}+\alpha_{N_{1}}\right) / \alpha_{L_{1}}$ is required.

Accuracy of 1 a. u. for $\Delta \rho(0)$ requires a relative accuracy of $0.7 \%$. With all this difficulty, however, such an experiment seems to be highly desirable.
Acknowledgment. - We are grateful to Dr. H. Kawakami, U. Fujita and E. Saito for their assistance in conversion measurement, and to Dr. T. Toriyama for his assistance in the Mössbauer measurements. The authors are also thankful to Prof. S. Suzuki, S. Yajima and Dr. I. Kawasuji for their cooperation in sample preparation.

\section{References}

[1] ShIRLeY, D. A., Rev. Mod. Phys. 36 (1964) 339.

[2] For an example : Duff, K. J., Phys. Rev. B 9 (1974) 66.

[3] Rǘggsegger, R. and KüNDIG, W., Phys. Lett. 39B (1972) 620.

[4] Emery, G. T., Ann. Rev. Nucl. Sci. 22 (1972) 165.

[5] Church, E. L., Bull. Amer. Phys. Soc. 12 (1967) 904.

[6] Anderson, E. M., Listengarten, M. A. and KhanonKIND, M. A., Izv. Akad. Nauk. Ser. Fiz. 34 (1970) 851.

[7] Band, I. M., Sliv, L. A. and Trzhakovskaya, M. B., Nucl. Phys. A 156 (1970) 170.

[8] RafF, U., Alder, K. and Baur, G., Helv. Phys. Acta 45 (1972) 427.

[9] Fujloka, M., U.S.-Japan Joint Seminar on Hyperfine Interactions Involving Excited Nuclei, Aug. 30-Sept. 1 (1972).

[10] Martin, B. and Schulé, R., Phys. Lett. 46B (1973) 367.
[11] Fujioka, M. and Hisatake, K., Phys. Lett. 40B (1972) 99.

[12] Shinohara, T. and Fujioka, M., Phys. Rev. B 7 (1973) 37.

[13] Qaim, S. M., Proc. Phys. Soc. 90 (1967) 1065.

[14] Johnson, D. P., Solid State Commun. 7 (1969) 1785.

[15] Nussbaum, R. H., Howard, D. G., Nees, W. L. and SteEN, C. F., Phys. Rev. 173 (1968) 653.

[16] Sawatzky, G. A., Van der Woude, F. and Morrish, A. H., Phys. Rev. 183 (1969) 383.

[17] FuJIOKa, M. and Hisatake, K., INS TL-89 (1966).

[18] ŠmáneK, E. and Wong, A. Y. C., Phys. Rev. 166 (1968) 348.

[19] Ingalls, R. L., Solid State Commun. 14 (1974) 11.

[20] Ingalls, R. L., Phys. Rev. 155 (1967) 157.

[21] FuJIOKA, M. and SHINOHARA, T., Nucl. Instrum. and Methods, to be published. 